\title{
Erratum to: Plastic litter accumulation on high-water strandline of urban beaches in Mumbai, India
}

\author{
H. B. Jayasiri • C. S. Purushothaman • A. Vennila
}

Published online: 1 June 2013

(C) Springer Science+Business Media Dordrecht 2013

Erratum to: Environ Monit Assess

DOI 10.1007/s10661-013-3129-z

There was a mistake in Figure $4 \mathrm{c}$ in the original publication of this article. The first bar of Fig. $4 \mathrm{c}$ representing the month "May" should be open ended with the value " $207 \pm 49$ " and without error bar. The correct figure is presented here.

The online version of the original article can be found at http:// dx.doi.org/10.1007/s10661-013-3129-z.

H. B. Jayasiri $(\varangle) \cdot$ C. S. Purushothaman $\cdot$ A. Vennila Aquatic Environment and Health Management Division, Central Institute of Fisheries Education,

Panch Marg, Versova, Mumbai 400-061, India

e-mail: hjayasiri@yahoo.com 


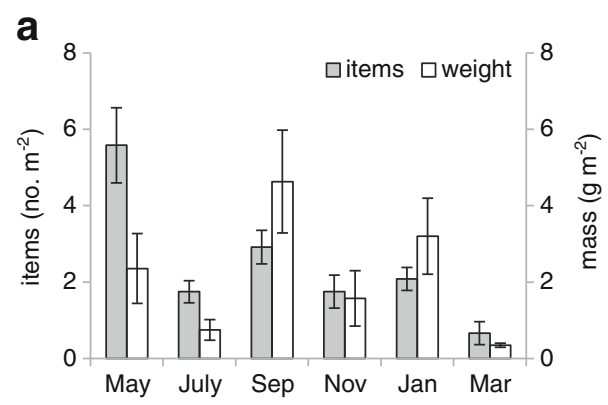

b
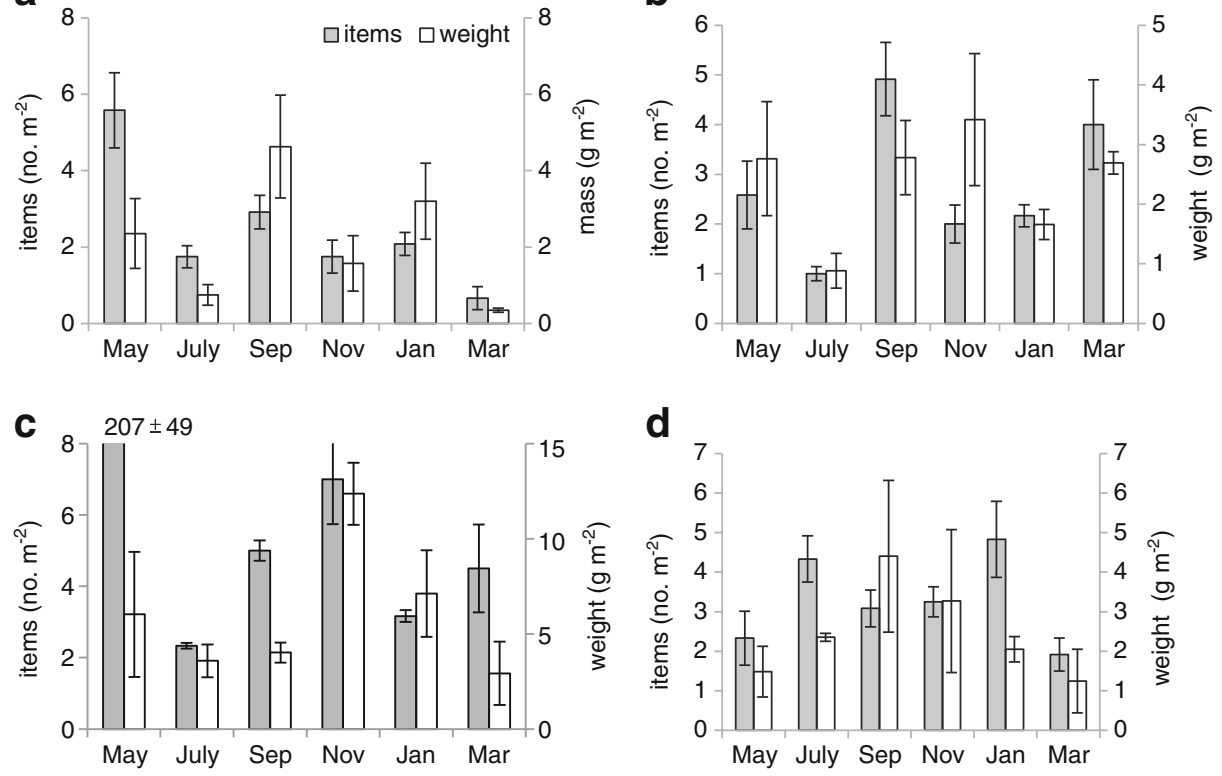

d

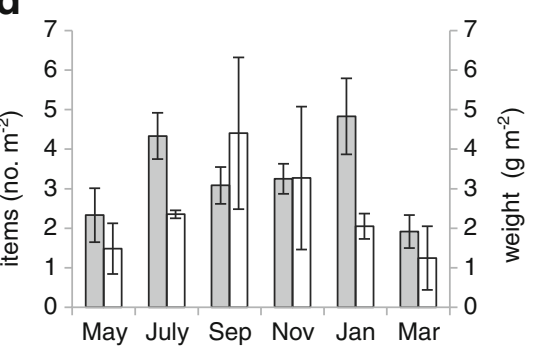

Fig. 4 Distribution of plastics (mean \pm SE) in beaches of Mumbai from May 2011 to March 2012: a Aksa, b Versova, $\mathbf{c}$ Juhu, d Dadar 